\title{
From amaurosis fugax to asymptomatic bithalamic infarct
}

\author{
H. Emond · T. Landis · F. Perren
}

Received: 4 June 2008/Revised: 29 October 2008/Accepted: 19 November 2008/Published online: 1 March 2009

(C) Springer-Verlag 2009

\begin{abstract}
Bilateral paramedian thalamic infarctions are usually associated with impaired consciousness, oculomotor disturbances and neuropsychological changes. A 44year-old healthy woman presented with amaurosis fugax of the right eye immediately after a Valsalva maneuver. Neurological examination, in particular visual acuity, vigilance and ocular movements, was normal. Blood pressure, ECG and angio-CT of the neck and head vessels were normal, but MRI/DWI and T2 sequences showed recent bithalamic ischemic lesions in the paramedian territories. Doppler sonography and transesophageal echocardiography showed a large right-to-left shunt due to an atrial communication, with septum aneurysm. Twenty-four-hours cardiac monitoring was normal but prior to an eventual closure of the cardiac defect she underwent an ambulatory 7-day ECG monitoring which revealed several paroxystic short lasting passages into atrial fibrillation, unnoticed by the patient. The interest in this case is threefold: (1) bilateral paramedian thalamic infarction which usually presents with a devastating clinical picture may occur clinically silent; (2) monocular amaurosis fugax which is usually associated with ipsilateral carotid disease may be the consequence of cardiac embolism, and (3) atrial fibrillation is never completely ruled out, here it was caught only in a 7-days ambulatory $R$-test, and consequently prevented closure of a possibly asymptomatic patent foramen ovale.
\end{abstract}

H. Emond · T. Landis · F. Perren $(\square)$

Department of Neurology, HUG, University Hospital

and Medical School of Geneva, Rue Micheli-du-crest 24,

1211 Geneva 14, Switzerland

e-mail: fabienne.perren@hcuge.ch
Keywords Stroke - Thalamic paramedian . Amaurosis fugax $\cdot$ Cardioembolism $\cdot$ Atrial fibrillation . PFO

\section{Introduction}

The classical paramedian artery syndrome accounts for $35 \%$ of thalamic infarcts and associates acute loss or impaired consciousness, followed by neuro-psychological disturbances and upward gaze limitation [1]. Bilateral paramedian thalamic infarctions account for one-third of paramedian infarcts because a unilateral paramedian pedicle may supply the paramedian territory on both sides [2]; they lead to more severe and longer-lasting symptoms than unilateral lesions and total recovery has been very rarely reported [3].

Here we report an atypical case of an asymptomatic acute bilateral paramedian infarction revealed by an amaurosis fugax.

\section{Case report}

A 44-year-old healthy woman without cardiovascular risk factors except moderate smoking (10 cigarettes/day) was admitted at our hospital because of a short lasting (a few minutes) loss of vision of the right eye. This happened just after a Valsalva maneuver. Neurological examination, blood pressure, ECG and CT-scan of the brain (including angiographic sequences which showed normal neck and head vessels) performed in the acute stage were normal. Three days later, diffusion-weighted images (DWI) and T2 sequences on MRI showed recent bi-thalamic ischemic lesions in the paramedian territories (Fig. 1). There were, 


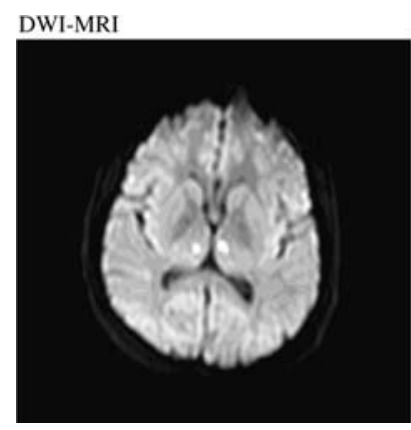

\section{T2-MRI}

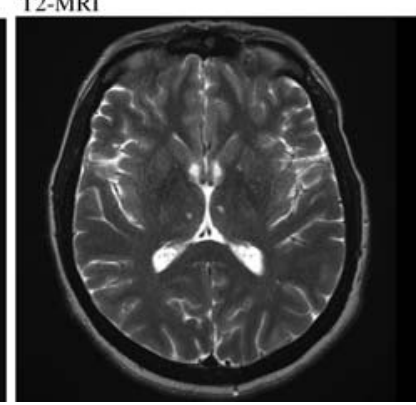

Fig. 1 Diffusion weighted (DWI) and T2 MRI sequences of the brain showing acute bilateral paramedian ischemic lesions

in particular no oculomotor disturbances and visual acuity was normal in both eyes. A comprehensive neuropsychological assessment was entirely normal. Laboratory blood tests showed a discrete hypercholesterolemia (total cholesterol $5.10 \mathrm{mmol} / \mathrm{L}$, total cholesterol/HDL index 5.67). Blood coagulation (factor V, factor VII, antithrombin, lupic anticoagulant) was normal. MR angiography and neurosonography showed normal extra- and intracranial vessels. However, Doppler sonography and transesophagal echocardiography showed a large right-to-left shunt due to a septum secundum type atrial communication with septum aneurysm. Since an embolic source was suspected, the patient was anticoagulated. Twenty-four-hour cardiac monitoring was normal but prior to an eventual closure of the cardiac defect she underwent an ambulatory 7-day ECG monitoring which revealed several paroxystic short lasting passages into atrial fibrillation, unnoticed by the patient. At 6-months follow-up, she remains asymptomatic under oral anticoagulant therapy and statins.

\section{Discussion}

Extracranial internal carotid disease is recognized as the first cause (45\%) of amaurosis fugax or retinal emboli [4]. However, cardiac lesions appear to be the second cause of importance [5]. When cardio-embolic origin of stroke is suspected, achieving the appropriate screening is crucial. Indeed, cardio-embolic origin, and especially right-to-left shunt, remain underdiagnosed because of non-systematic use of transcranial Doppler and TEE in case of retinal infarct [4]. Furthermore, atrial fibrillation and flutter remain the most frequent cause of cardio-embolic stroke, but frequently escape from standard ECG or Holter monitoring [6]. Here, the extensive screening for a cardioembolic origin of the monocular amaurosis fugax, (a transient ischemia in the territory of the ophthalmic artery) revealed acute, but asymptomatic, bi-thalamic infarcts probably due to concomitant cardiogenic emboli in another arterial territory, that of the paramedian thalamic artery, which are clinically unrelated to the amaurosis fugax.

The interest in this case is threefold: (1) bilateral paramedian thalamic infarction which usually presents with a devastating clinical picture may occur clinically silent. The integrity of intralaminar nuclei and ascending pathways from the reticular formation might explain this exceptional asymptomatic presentation; (2) monocular amaurosis fugax which is usually associated with ipsilateral carotid disease may be the consequence of cardiac embolism, and (3) atrial fibrillation is never completely ruled out. Here it was caught only in an ambulatory 7-day ECG monitoring, which prevented from closing a possibly asymptomatic patent foramen ovale.

\section{References}

1. Bogousslavsky J, Regli F, Uske A (1988) Thalamic infarcts: clinical syndromes, etiology, and prognosis. Neurology 38:837847

2. Percheron G (1976) Les Artères du Thalamus Humain. II.-Artères et territoires thalamiques paramédians de l'artère basilaire communicante. Rev Neurol 132:309-324

3. Krolak-Salmon P, Croisile B, Houzard C et al (2000) Total recovery after bilateral paramedian thalamic infarct. Eur Neurol $44: 216-218$

4. Kramer M, Goldenberg-Cohen N, Shapira Y et al (2001) Role of transesophageal echocardiography in the evaluation of patients with retinal artery occlusion. Ophtalmology 108:1461-1464

5. Babikian V, Wijman C, Koleini B et al (2001) Retinal ischemia and embolism. Cerebrovasc Dis 12:108-113

6. Jabaudon D, Sztajzel J, Sievert K et al (2004) Usefulness of ambulatory 7-day ECG monitoring for the detection of atrial fibrillation and flutter after acute stroke and transient ischemic attack. Stroke 35:1647-1651 